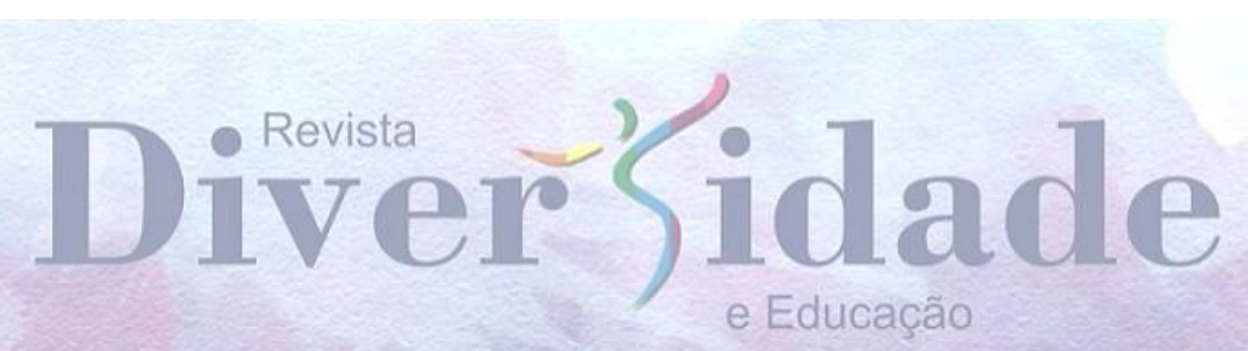

\title{
DIVISÃO SEXUAL DO TRABALHO E MULHERES NAS CARREIRAS DE CIÊNCIAE TECNOLOGIA
}

\section{DIVISIÓN SEXUAL DEL TRABAJO Y MUJERES EN LAS CARRERAS DE CIENCIA E TECNOLOGÍA}

\section{SEXUAL DIVISION OF LABOR AND WOMEN IN SCIENCE AND TECHNOLOGY CAREERS}

\author{
Bruna de Oliveira Gonçalves ${ }^{1}$ \\ Raquel Quirino ${ }^{2}$
}

RESUMO: A divisão sexual do trabalho é a teoria que permite compreender os caminhos profissionais femininos marcadamente diferentes dos traçados pelos homens. Além disso, explica que a valorização do trabalho executado pela mulher é diferente daquele feito pelo homem. Ainda que de forma tímida, as mulheres vêm mudando o status quo e adentrando em áreas que se configuraram como redutos masculinos, como, por exemplo, as áreas de Ciências e Tecnologia (C\&T). Nesse contexto, o presente artigo discute a divisão sexual nas áreas de C\&T e evidencia o que a literatura científica tem apontado: os princípios da divisão sexual do trabalho permanecem inalterados, apesar de pequenos deslocamentos e de novas configurações.

PALAVRAS-CHAVE: Divisão sexual do trabalho. Mulheres nas carreiras da Ciência e Tecnologia. Engenheiras

RESUMEN: La división sexual del trabajo es la teoría que permite comprender los caminos profesionales femeninos marcadamente diferentes del trazado por los hombres. Además, explica que la valorización del trabajo realizado por una mujer es diferente de aquel hecho por hombre. Aunque de forma tímida, las mujeres vienen cambiando el status quo y adentrando en áreas que se configuraron como reductos masculinos, como, por ejemplo, las áreas de ciencia y tecnología (C\&T). En ese contexto, lo presente artículo discute la división sexual en las áreas de C\&T y evidencia lo que la literatura científica ha señalado: los principios de la división

\footnotetext{
${ }^{1}$ Mestranda do Programa de Pós Graduação em Educação Tecnológica do CEFET-MG, na linha de pesquisa "processos formativos em educação tecnológica". Investiga violência simbólica, sexismo, estereótipos e marcadores de gênero nos cursos de Engenharia do CEFET-MG, tendo como teoria de base principal a divisão sexual do trabalho a partir de teóricas da sociologia do trabalho francesa. Integrante da linha 2 do Grupo de Pesquisa em Formação e Qualificação Profissional (FORQUAP), do CEFET-MG.

${ }^{2}$ Pós-doutorado e Doutorado em Educação pela UFMG; Mestrado em Educação Tecnológica, Professora do Programa Especial de Formação Pedagógica de Docentes e do Programa em Pós-Graduação em Educação Tecnológica; Coordenadora do Grupo de Pesquisa em Formação e Qualificação Profissional - FORQUAP no CEFET-MG. Pesquisadora e Docente nas áreas: Trabalho-Educação; Relações de Gênero na Ciência \& Tecnologia, no Trabalho e na Educação Profissional; Didática e Formação Docente. Atua também como Consultora e Palestrante Educacional e Organizacional.
} 
sexual del trabajo permanecen inalterados, a pesar de pequeños desplazamientos y nuevas configuraciones.

PALABRAS CLAVE: División sexual del trabajo. Mujeres em las carreras de la Ciencia e Tecnología. Ingenieras.

ABSTRACT: The sexual division of labor is the theory that makes us understand the female professional forms, which are markedly different from the forms traced by men. It also explains that the valuation of the work done by woman is different from the work done by man. Even though in a shy way, women has been changing their status quo and begin to participated in areas dominated by men, as in the case of Science and Technology (C\&T). In this context, the present article deliberate a sexual division in the C\&T areas and evidences what the scientific literature has pointed out: the sexual division of labor principles are still unchanged, although it has small displacements and new configurations.

KEYWORDS: Sexual division of labor. Women in science and technology careers. Engineering.

\section{Introdução}

A análise demográfica do censo de 2010, do Instituto Brasileiro de Geografia e Estatística, quanto às estatísticas de gênero, revela que, no Brasil, o nível educacional das mulheres é maior que o dos homens. No entanto, em se tratando de áreas de formação profissional, as "escolhas" delas por determinadas áreas em detrimento de outras implicam em uma relação assimétrica no mundo do trabalho (IBGE, 2014). Na literatura científica, o fenômeno que auxilia a compreensão das escolhas das mulheres por caminhos marcadamente diferentes daqueles escolhidos ou seguidos pelos homens é conhecido como "segregação horizontal". Quanto à dificuldade delas de ascenderem profissionalmente, denomina-se “segregação vertical” ou "teto de vidro" (OLINTO, 2011).

A partir do estudo da divisão sexual do trabalho e de seus princípios norteadores é possível compreender tais relações sociais antagônicas e conflituosas entre homens e mulheres na sociedade, permeadas pelas construções de gêneros, a partir de uma base material: a categoria "trabalho" e sua divisão desigual entre os sexos (HIRATA e KÉRGOAT, 2007). Destarte o presente texto discute a divisão sexual do trabalho nas carreiras de ciência e tecnologia.

\section{Divisão sexual do trabalho: Breves considerações}

“A divisão sexual do trabalho é a forma de divisão do trabalho social decorrente das relações sociais entre os sexos" (HIRATA e KERGOAT, 2007, p. 599), sendo fator prioritário 
para a sobrevivência destas. Nesse caso, conjuga-se "relação" não como um contato ou ligação social. Configura-se, na verdade, como "uma tensão que atravessa o campo social”. Essa forma de divisão do trabalho é modulada histórica e socialmente e "tem como características a designação prioritária dos homens à esfera produtiva e das mulheres à esfera reprodutiva e, simultaneamente, a apropriação pelos homens das funções com maior valor social adicionado (KÉRGOAT, 2009, p.67)”.

Cisne (2014, p. 88-89) corrobora tal assertiva ao afirmar que "a divisão sexual do trabalho deve ser entendida como base das assimetrias e hierarquias contidas nessa divisão, e que se expressam nas carreiras, nas qualificações e nos salários entre os sexos" e constitui-se na "base estruturante da exploração e da opressão da mulher".

A divisão do trabalho entre os sexos se configura a partir de dois princípios norteadores: (i) o princípio da separação: existem trabalhos destinados aos homens e outros diferentes destinados às mulheres; e o (ii) princípio hierárquico, anunciando o maior valor social e econômico agregado ao trabalho dos homens (HIRATA e KERGOAT, 2007; KERGOAT, 2009).

A divisão sexual do trabalho foi objeto de estudo em diversos países, mas foi na França, no início dos anos de 1970, sob o impulso do movimento feminista, que surgiram trabalhos cuja base teórica do conceito se assentaria (HIRATA e KÉRGOAT, 2007). Foi a consideração do trabalho doméstico simultânea a do trabalho profissional que permitiu se pensar em termos de "divisão sexual do trabalho". Assim, o trabalho doméstico deixa de ser um apêndice do assalariado e se torna campo de estudo.

Tal divisão entre as esferas produtiva e reprodutiva fortaleceu a hierarquia e a desigualdade entre homens e mulheres, uma vez que, o campo da produção e de riquezas, de valorização é masculino e a esfera da reprodução social - atividades que garantem a reprodução da força de trabalho -, é um espaço feminino (CISNE, 2014). E, “mesmo quando a mulher desempenha uma função remunerada fora do lar, continua a ser responsabilizada pela tarefa de preparar as gerações mais jovens para a vida adulta (SAFIOTTI, 1987, p.8).”.

Os conceitos de exclusão vertical e horizontal trazidas por Olinto (2011) dialogam com os princípios organizadores do trabalho expostos pelas teóricas feministas da sociologia do trabalho de base francesa. Assim como no primeiro princípio organizador, a exclusão vertical evidencia que as escolha profissionais das mulheres são marcadamente diferentes das dos homens. Já o princípio da hierarquia pode ser mais bem compreendido quando se adiciona ao conceito de exclusão vertical. Diante da valorização diferenciada do trabalhado exercido por homens e mulheres, as dificuldades sutis, porém reais, que elas enfrentam para ascenderem 
profissionalmente, ocasiona a exclusão vertical, também conhecida pela metáfora do teto de vidro (LIMA, 2013).

\section{Mulheres nas carreiras de $\mathrm{C} \& \mathrm{~T}$}

Segundo Cabral (2006) a associação da masculinidade ao que é científico e a feminilidade ao que não é, é um mito presente dentro e fora dos círculos científicos, de que a ciência é de gênero neutro. Ora, discutir gênero, ciência e tecnologia implica em "considerar o conhecimento científico como não neutro em termos de valores, questionar a objetividade científica como estritamente racional e também seu status de verdade na construção do conhecimento (CABRAL, 2006, p.84).” A tecnologia e a ciência não estão restritas apenas às esferas técnicas, à produção do conhecimento e a seus arranjos organizacionais; não se pode ignorar a cultura em que estão inseridas.

Vencendo desafios, resistindo e não se deixando dominar por preconceitos e discriminações, as mulheres transgredem cotidianamente as regras de uma sociedade patriarcal e androcêntrica e conquistaram espaços, abrindo caminhos para as futuras gerações (CARVALHO e CASAGRANDE, 2011). Nesse exercício de cidadania, Tabak (2015) confirma que no Brasil as mulheres estão se tornando mais visíveis no campo da Ciência e Tecnologia, apesar dos números ainda insatisfatórios.

É, portanto, uma falácia afirmar a inaptidão das mulheres para a atividade científica, assim como dizer que não elas não se interessam pela área e não têm competência para desenvolver pesquisas científicas e tecnológicas de ponta (TABAK, 2015). Muitas vezes, por ser associada a valores como emoção, fragilidade e insegurança, a mulher é vista como incapaz de usar a razão. Esses traços de personalidade construídos ao longo do processo de socialização contribuem para que as próprias mulheres acreditem que são menos racionais e, logo, inaptas para a atividade científica (SAFFIOTI, 1987).

Na mesma perspectiva, Lombardi (2009), esclarece que as relações sociais de sexo perpassam, especificamente, a área profissional da engenharia e "[...] repousam, em primeiro lugar, sobre uma relação hierarquizada entre homens e mulheres, tratando-se de uma relação de dominação e de poder do grupo de engenheiros do sexo masculino sobre o grupo de engenheiras (LOMBARDI, 2009, p.110).”.

Carrilho e Yannoulas (2011), ao adotar o pressuposto da divisão sexual do trabalho como base material para as relações conflituosas entre os sexos na sociedade, consideram que desde a infância as meninas são encaminhadas para áreas que envolvem o cuidado com o 
próximo, sendo desencorajadas, ainda que de forma velada, ao estudo das ciências exatas, uma vez ser esse campo compreendido como masculino.

Lombardi (2013), ao levantar hipóteses para explicar a discreta presença das mulheres na Engenharia, evidencia algumas limitações impostas pela profissão, tais como sua origem miliar, as condições adversas de algumas especialidades, o comando de equipes masculinas e a ideia da incompatibilidade entre Engenharia e uma dada concepção de feminino, contrária à matemática, à racionalidade, à objetividade, à não predisposição à competição, características atribuídas à Engenharia e ao masculino.

Desde a década de 1980 pesquisadoras brasileiras estudam a baixa participação feminina em carreiras da ciência e tecnologia de forma geral, e particularmente nas engenharias. Para isso, investigam dados, discursos de estudantes, docentes e profissionais, contribuindo, assim, para a construção de uma massa crítica interpretativa a respeito da defasagem, do perfil e das trajetórias das pioneiras de diversas áreas (LOMBARDI, 2013).

A sub-representação feminina nas Engenharias está associada à discriminação de gênero no ambiente de trabalho. Isso acontece quando, no exercício profissional, se atribuem às mulheres determinadas áreas de trabalho e certas atividades profissionais, em detrimento de outras, por exemplo. Lombardi (2006) aponta que uma das maiores barreiras encontradas pelas engenheiras em suas carreiras é a de ascender a postos de comando nas organizações. No entanto, essa limitação é verificada para as trabalhadoras de uma forma geral. Para ascenderem hierarquicamente, as mulheres têm, de maneira recorrente, suas competências profissionais colocadas em prova, o que não se constata no caso masculino, sendo, portanto, um diferencial de gênero.

Carrilho e Yannoulas (2011) esclarecem que há também subdivisões nas engenharias, sendo aquelas consideradas "duras", detentoras de maior base tecnológica, praticamente um monopólio masculino, corroborando a afirmação de Hirata (2007, p. 145) de que a "tecnologia se conjuga no masculino." Apesar das tecnologias permitirem romper com padrões estabelecidos de segregação de sexo das ocupações e profissões, a divisão sexual do trabalho tem permanecido estável, ainda que a natureza do trabalho e a qualificação para desempenhálo se transformaram radicalmente. Por não ser força independente, a maneira que a tecnologia repercute na natureza do trabalho é determinada pelas relações (pré) existentes (CARRILHO E YANNOULAS, 2011).

\section{Considerações finais}


Pelo exposto, apreende-se que apesar das diversas conquistas auferidas pelas mulheres no mundo do trabalho e acadêmico, inclusive em áreas pouco usuais de atuação feminina, os princípios organizadores da divisão sexual permanecem inalterados. Assim, são evidenciados pequenos deslocamentos e atitudes de enfrentamento e rompimento com padrões socialmente estabelecidos, mas, via de regra, as mulheres continuam a traçar caminhos profissionais marcadamente diferentes dos seguidos pelos homens e são menos valorizadas.

Ainda quando transgridem o status quo e buscam traçar seu caminho por vias consideradas redutos masculinos, as dificuldades de permanência e ascensão na carreira escolhida evidenciam segregações, desvalorização do trabalho da mulher e a criação de guetos femininos em funções precárias e desqualificadas, apesar de sua maior qualificação em comparação aos homens.

\section{Referências}

CABRAL, Carla Giovana. Pelas telas, pelas janelas: o conhecimento dialogicamente situado. Cadernos Pagu, n. 27, jul./dez.2006. Disponível em: < http://www.scielo.br/scielo.php?pid=S010483332006000200005\&script=sci_abstract\&tlng=p t>. Acesso em 15 de Agosto de 2017.

CARRILHO, Anabelle e YANNOULAS, Silvia Cristina. Construindo novos túneis: subterfúgios das engenheiras para deslocar as fronteiras da divisão sexual da ciência e da tecnologia. INTERthesis, Florianópolis, v.8, nº2, jul/dez. 2011. Disponível em: < https://periodicos.ufsc.br/index.php/interthesis/article/view/1807-1384.2011v8n2p36>.

Acesso em 21 de Agosto de 2017.

CARVALHO, Marília Gomes de; CASAGRANDE, Lindamir Salete. Mulheres e ciência: desafios e conquistas. INTERthesis, Florianópolis, v.8, n² 2, jul./dez. 2011. Disponível em: < https://periodicos.ufsc.br/index.php/interthesis/article/view/1807-1384.2011v8n2p20 >.

Acesso em 15 de Agosto de 2017.

CISNE, Mirla. Feminismo e consciência de classe no Brasil. São Paulo: Cortez, 2014. HIRATA, Helena; KERGOAT, Danièle. Novas configurações da divisão sexual do trabalho. Cadernos de Pesquisa, v. 37, n. 132, set./ dez. 2007. Disponível em: http://scielo.br/pdf/cp/v37n132/a0537132. Acesso em: 20 de Dezembro de 2016.

IBGE. Estatística de Gênero: uma análise dos resultados do censo demográfico 2010. Disponível em: <http://biblioteca.ibge.gov.br/visualizacao/livros/liv88941.pdf >. Acesso em: 5 de Dezembro de 2017.

KERGOAT, Danièle. Título do capítulo. In: HIRATA, Helena (org). Dicionário crítico do feminismo. São Paulo: UNESP, 2009. 
LIMA, Betina Stefanello. O labirinto de cristal: as trajetórias das cientistas na física. Estudos Feministas, Local, v.21, edição 3, dez/2013. Disponível em: $\leq$ http://www.forquap.cefetmg.br/galerias/arquivos download/Labirinto de cristal mulheres na fisica.pdf. >. Acesso em 05 de Dezembro de 2017.

LOMBARDI, Maria Rosa. Engenheira \& gerente: desafios enfrentados por mulheres em posições de comando na área tecnológica. Revista Tecnologia e Sociedade, Curitiba, v.2, n³, 2006. Disponível em: < https://periodicos.utfpr.edu.br/rts/article/viewFile/2485/1599>. Acesso em 05 de Dezembro de 2017.

LOMBARDI, Maria Rosa. Formação e docência em Engenharia na ótica do gênero: um balanço de estudos recentes e dos sentidos da feminização. In: YANNOULAS, Silvia. Trabalhadorasanálise da Feminização das Profissões e Ocupações. Brasília: Editorial Abaré, 2013, p. 111136.

OLINTO, Gilda. A inclusão das mulheres nas carreiras de ciência e tecnologia no Brasil. Incl. Soc., Brasília, v. 5, n. 1, jul./dez. 2011. Disponível em:

<http://revista.ibict.br/inclusao/article/view/1667>. Acesso em: 26 de Abril de 2017.

SAFFIOTI. Heleieth. O poder do macho. Rio de Janeiro: Moderna, 1987, v.10.

TABAK, Fanny. Apesar dos avanços: obstáculos ainda persistem. Cadernos de Gênero e Tecnologia, Curitiba, n³3, jan./jun. 2015. Disponível em: < https://periodicos.utfpr.edu.br/cgt/article/view/6164/3815>. Acesso em 15 de Agosto de 2017. 